Check for updates

Cite this: RSC Adv., 2019, 9, 4797

Received 25th January 2019

Accepted 1st February 2019

DOI: 10.1039/c9ra00671k

rsc.li/rsc-advances

\section{Plasma-deposition of $\alpha-F e O O H$ particles on biochar using a gliding arc discharge in humid air: a green and sustainable route for producing oxidation catalysts $\uparrow$}

\author{
Antoine Tiya-Djowe, (D) * Marie-Anne Dourges, Jean-Luc Bruneel \\ and Hervé Deleuze*
}

\begin{abstract}
Non-thermal atmospheric plasma of the gliding arc type was used as a tool for goethite-on-biochar hybrid material preparation. Biochars were first prepared by carbonizing raffia bamboo (the leafstalk of raffia palm) pith at $300^{\circ} \mathrm{C}(\mathrm{BC} 3), 500^{\circ} \mathrm{C}(\mathrm{BC} 5)$ and $700^{\circ} \mathrm{C}(\mathrm{BC} 7)$. A suspension of each biochar in $\mathrm{Fe}^{2+}$ aqueous solution was then exposed to a plasma discharge burning in humid air. $\alpha$-FeOOH particles were thus formed and spontaneously deposited on the biochar surface. In order to investigate the effect of plasma species on the support during goethite deposition, biochars were also treated with plasma in the absence of $\mathrm{Fe}^{2+}$ ions and then characterized. Results revealed a substantial hydroxylation and slight $\mathrm{N}$-doping of biochar after plasma treatment. The prepared composite materials were tested in oxidative degradation of nitroresorcinol. The catalytic performances were in the order Fe-BC3 < Fe-BC7 < Fe-BC5 according to the abatement efficiency and half-time values obtained for each catalyst. This study establishes that waste biomass and atmospheric air can be simultaneously valorised for green production of heterogeneous catalysts.
\end{abstract}

\section{Introduction}

For several decades, the use of agricultural waste as raw material has been developed for the production of chemicals with high added value, ${ }^{1-6}$ green fuels ${ }^{7}$ and biochars. ${ }^{8-10}$ The potential of biochars (i.e. carbon-rich materials obtained from biomass pyrolysis under an oxygen-limited atmosphere ${ }^{\mathbf{1 1}}$ ) has been proven in environmental remediation. For instance, biochars have been intensively used as adsorbents for the removal of both organic and inorganic pollutants from water ${ }^{12-14}$ and as catalysts for persulfates and hydrogen peroxide activation. ${ }^{15-18}$ In addition, biochars have been used as bio-based supports for heterogeneous catalysts preparation. ${ }^{19-21}$ While using biochar as a catalyst support, a substantial dual functionality in biocharmetal oxide composites such as $\mathrm{TiO}_{2}$-biochar ${ }^{22}$ and $\mathrm{Co}_{2} \mathrm{O}_{3}-$ biochar $^{23}$ has been proven in oxidative degradation of organic pollutants. Accordingly, the future prospects of using biochar in heterogeneous catalysis appear very bright. The present study aims at producing iron oxide/biochar hybrid materials using a green, versatile, cheap and efficient technique based on the use of gliding arc plasma (hereafter called glidarc) at

Institut des Sciences Moléculaires (ISM, CNRS-UMR 5255), Université de Bordeaux, 351 cours de la Libération, 33405 Talence Cedex, France. E-mail: antoine. tiyadjowe@yahoo.com; herve.deleuze@u-bordeaux.fr

$\dagger$ Electronic supplementary information (ESI) available. See DOI: 10.1039/c9ra00671k atmospheric pressure, and demonstrating the potential use of the target materials as catalysts in the oxidative degradation of organic pollutants.

The glidarc plasma invented by Lesueur et al. in 1988 (ref. 24) and later used by Czernichowski et al. for the valorization of gases $^{25}$ is a process in which the plasma plume is generated by an electric arc created between two (or more) metallic electrodes connected to a high voltage transformer. The electrodes are symmetrically disposed on the sides of an atomizing nozzle. The electric arc can then be pushed away by a gas flow and glides along the electrodes until it is short-circuited by a new arc and the cycle resumes. During the gliding process, the ionized channel of the arc lengthens as it progresses, its volume increases and subsequently its temperature decreases before it bursts into a plume of quenched plasma. The plasma plume is known to contain various species including electrons, cations and free radicals whose reactivity can be deployed for chemical transformations of either solid or liquid target. Those species are produced from the cleavage of bonds in gas molecules via non-elastic impacts with electrons. When humid air is used as feeding gas, the $\mathrm{NO}^{\circ}$ and $\mathrm{HO}^{*}$ radicals are mainly formed. ${ }^{26}$

The glidarc technology has been recently developed for the synthesis of nanostructured metal oxides including $\mathrm{TiO}_{2},{ }^{27} \alpha$ $\mathrm{FeOOH}^{28}$ and $\mathrm{MnO}_{2}{ }^{29}$ the process consisting in successive oxidation (or reduction) and hydrolysis of a cationic (or anionic) metal precursors dissolved in aqueous medium to form the 
corresponding oxide. In such process, $\mathrm{HO}^{\bullet}$ radicals with very high oxidizing potential $\left[E^{\circ}\left(\mathrm{HO}^{*} / \mathrm{H}_{2} \mathrm{O}=2.44 \mathrm{~V} / \mathrm{SHE}\right)\right]$ have been proven to be the main reagent that intervenes during the synthesis of $\mathrm{TiO}_{2}$ and $\alpha$-FeOOH from titanium(III) chloride and iron(II) sulphate respectively. ${ }^{27,28}$ In the case of $\mathrm{MnO}_{2}$, permanganate ions were reduced by $\mathrm{NO}^{\circ}$ radicals $\left[E^{\circ}\left(\mathrm{NO}_{3}{ }^{-} / \mathrm{NO}^{\circ}=0.94\right.\right.$ $\mathrm{V} / \mathrm{SHE})] .^{29}$ Nevertheless, the mechanism of humid air plasma synthesis of metal oxides is still not well understood owing to the presence of numerous secondary species including $\mathrm{H}_{2} \mathrm{O}_{2}$, $\mathrm{NO}_{2}, \mathrm{HONO}, \mathrm{HNO}_{3}$ and $\mathrm{HO}_{2}$ that are formed by radicals recombination in gas phase $\mathrm{e}^{30}$ and may also react with the solute once in liquid phase.

Herein, the gliding arc plasma burning in humid air is used for the first time for the preparation of $\alpha$-FeOOH@biochar composites. The biochars used in this study were obtained by carbonizing raffia bamboo, i.e. the leafstalk of raffia Vinifera palm, a waste bio-based material that is very abundant in central Africa where it is traditionally used by local populations as firewood and as building material. ${ }^{31}$ The composites were characterized using various methods for determining structure and porosity. Structural modifications of the support (i.e. biochar) during the plasma deposition process were also addressed. The as prepared materials were tested as catalysts for degradation of nitroresorcinol. Indeed, the oxidative degradation of organic molecules by using iron oxides based catalysts (namely the Fenton-like reaction) has been extensively studied since several decades. ${ }^{32,33}$ In such reaction, the $\mathrm{HO}^{\circ}$ radicals produced from the decomposition of hydrogen peroxide catalysed by the iron species act as oxidizing reagents for total degradation of organic pollutants. Nitroresorcinol was chosen as model nitrophenol pollutant because of its tremendous use in polymers industry. ${ }^{34}$

\section{Experimental}

\subsection{Biochars preparation}

Biochars used as supports in this work were made by slow pyrolysis of raffia bamboo pith. Raffia bamboos were harvested in a farm at Babadjou (west region of Cameroon, central Africa) and cut into $10 \mathrm{~cm}$ length pieces. Each piece was thoroughly washed with pure water and dried in an oven at $110^{\circ} \mathrm{C}$ for 24 hours. Subsequently, the shell was manually separated from the pith. Afterwards, the pith was cut into small cylinders (diameter $\approx 1 \mathrm{~cm}$; height $\approx 0.5 \mathrm{~cm}$ ) and then carbonized. Three different heating programs were used as presented in Fig. $\mathrm{S} 1 . \dagger$ The first program consisted at heating the raw material from $20{ }^{\circ} \mathrm{C}$ to $300{ }^{\circ} \mathrm{C}$ (heating rate of $2.3^{\circ} \mathrm{C} \mathrm{min}^{-1}$ ) and to keep it at the final temperature for $4 \mathrm{~h}$. For the second program, the biomass was first heated from $20{ }^{\circ} \mathrm{C}$ temperature to $300{ }^{\circ} \mathrm{C}$ at $2.3{ }^{\circ} \mathrm{C} \mathrm{min}^{-1}$. After a plateau of $4 \mathrm{~h}$ at $300{ }^{\circ} \mathrm{C}$, the material was further heated up to $500{ }^{\circ} \mathrm{C}$ at $2.3{ }^{\circ} \mathrm{C} \min ^{-1}$ and kept at this final temperature for $2 \mathrm{~h}$. The third program was similar to the second, the only difference being the target calcination temperature $\left(700{ }^{\circ} \mathrm{C}\right)$. Carbonization was made in a tubular furnace under nitrogen atmosphere $\left(\mathrm{N}_{2}\right.$ flow rate $\left.=200 \mathrm{~mL} \min ^{-1}\right)$. Next, all the carbonized samples were grounded to pass a $0.315 \mathrm{~mm}$ sieve. The final products were referred as BCT, in which $T$ represents the final calcination temperature $(T=3,5$ and 7 corresponding to 300,500 and $700{ }^{\circ} \mathrm{C}$ respectively).

\subsection{Plasma-deposition process}

The goethite deposition process was done in a gliding arc plasma batch reactor. To this end, $0.5 \mathrm{~g}$ of biochar was dispersed in a $350 \mathrm{~mL}$ solution containing $2.4 \mathrm{~g}(0.0084 \mathrm{~mol})$ of iron sulphate heptahydrate from Aldrich $\left(\mathrm{FeSO}_{4} \cdot 7 \mathrm{H}_{2} \mathrm{O}\right.$; purity $\left.=99.997 \%\right)$. The whole was then stirred vigorously for $30 \mathrm{~min}$ to achieve good dispersion of biochar particles. Afterward, the mixture was transferred into the plasma reactor and exposed to the discharge for $1 \mathrm{~h}$ under magnetic stirring. After the discharge was switched off, the mixture was further aged (with magnetic stirring) at $98{ }^{\circ} \mathrm{C}$ under reflux for $8 \mathrm{~h}$. At the end of ageing process, the material was collected by vacuum filtration using a $0.45 \mu \mathrm{m}$ Teflon Millipore filter, washed repeatedly with deionised water and dried at $110^{\circ} \mathrm{C}$ for $24 \mathrm{~h}$. The resulting material was named as Fe-BCT. An aqueous suspension of each biochar without iron sulphate was also treated with plasma and the resulting material was name as P-BCT. Finally, the bulk $\alpha-\mathrm{FeOOH}$ was synthesized following the same procedure as for Fe-BCT materials. The design of the plasma reactor used in this research consists in a pair of aluminium electrodes connected to an AC $220 \mathrm{~V} / 10 \mathrm{kV}-0.1 \mathrm{~A}$ which deliver a mean voltage of $600 \mathrm{~V}$ under operating condition (Fig. S2 $\dagger$ ). Synthetic air from Alphagaz France $\left(80 \% \mathrm{O}_{2}+20 \% \mathrm{~N}_{2}\right)$ was used as feeding gas and was saturated with water vapour by passing through a bubbling flask containing distilled water at $25{ }^{\circ} \mathrm{C}$ before being blown between the electrodes at the flow rate of $400 \pm 10 \mathrm{~L} \mathrm{~h}^{-1}$ via a $1 \mathrm{~mm}$ size atomizing nozzle. During the process, the reactor was cooled down by using a water circulating bath and the temperature was maintained at $25{ }^{\circ} \mathrm{C}$ in order to limit evaporation and vapour stripping.

\subsection{Materials characterization}

X-ray diffraction analyses were performed on a D2 Phaser diffractometer (Bruker) using $\mathrm{K} \alpha$ radiation of $\mathrm{Cu}(\lambda=1.5418 \AA)$. The diffraction patterns were recorded from 5 to $70^{\circ}$ (2 theta values) at a rate of $1.2^{\circ} \mathrm{min}^{-1}$, with the machine operated at 30 $\mathrm{kV}$ and $10 \mathrm{~mA}$. Raman spectra were recorded using a Xplora Raman spectrometer (Horiba Scientific) with a confocal microscope at room temperature. The experiments were carry out with the $532 \mathrm{~nm}$ excitation wavelength and the $50 \times$ objective was used. Unless otherwise stated, $1 \%$ of total laser power (12 $\mathrm{mW}$ ) was used. The number of scans was 3 , and the time of accumulation was $300 \mathrm{~s}$ per scan. Several spots of each sample were analysed to ascertain the representativity of the results. Fourier transformed infra-red spectra were taken on pellets of grounded samples (1 $\mathrm{mg}$ of material diluted in $200 \mathrm{mg}$ of analytical grade $\mathrm{KBr}$ ) by using a Nicolet 750 FTIR spectrometer (Thermo Fisher Scientific, Waltham, MA, USA). The transmission spectra were obtained by recording 100 scans between 450 and $4000 \mathrm{~cm}^{-1}$ with a resolution of $4 \mathrm{~cm}^{-1}$. XPS analyses were performed on a ThermoFisher Scientific K-alpha spectrometer. Monochromatic $\mathrm{Al} \mathrm{K} \alpha$ radiation $(1486.6 \mathrm{eV})$ was operated under a residual pressure of $10^{-7}$ Pa during analysis. The full (0-1150 eV) and high resolution spectra were obtained 
with constant pass energy of $200 \mathrm{eV}$ and $40 \mathrm{eV}$ respectively. Charge neutralization was applied for all samples. High resolution spectra were fitted and quantified using the AVANTAGE software provided by ThermoFisher Scientific and the Scofield sensitivity factors available from the internal database. The thermal behaviour of materials was studied by using a NETZSCH STA 409C/CD (Erich NETZSCH GmbH \& Co. Holding KG, Selb, Germany) thermogravimetric analyzer. For this purpose, about $10 \mathrm{mg}$ of each sample was heated from $30{ }^{\circ} \mathrm{C}$ to $1000{ }^{\circ} \mathrm{C}$ (heating rate of $10^{\circ} \mathrm{C} \mathrm{min}^{-1}$ ) under air atmosphere. Surface morphologies of all the samples were observed by scanning electron microscopy (SEM EVO 50, Zeiss) equipped with a EDS analyser at an acceleration voltage of $15 \mathrm{kV}$. The textural properties were analysed by nitrogen physisorption using a Micromeritics ASAP 2010 analyzer (Micromeritics Corp., Norcross, GA, USA). Prior to analysis, all the samples were outgassed at $150{ }^{\circ} \mathrm{C}$ under vacuum for $24 \mathrm{~h}$. The BET and $t$-plot methods were respectively used to determine the total and microporous surface area whereas the slit pore geometry model of Horvath and Kawazoe was used for evaluating micropores size. The total volume of pores was calculated at $P / P_{0}=0.9908$ while the BJH equation applied to the adsorption branch was used for determining the mesopores volume.

\subsection{Catalytic activity test}

The prepared materials were tested as $\mathrm{H}_{2} \mathrm{O}_{2}$ activation catalysts for oxidative degradation of nitroresorcinol (Alfa Aesar, 98\%) in water. The chemical structure and UV-vis spectrum of nitroresorcinol are depicted in Fig. S3. $\dagger$ In a typical experiment, $0.2 \mathrm{~g}$ of catalyst was dispersed into $200 \mathrm{~mL}$ solution of pollutant $\left(20 \mathrm{mg} \mathrm{L}^{-1} ; \mathrm{pH}=4\right)$ at $25^{\circ} \mathrm{C}$ and of $\mathrm{H}_{2} \mathrm{O}_{2}(5 \mathrm{mM})$ was then quickly added to initiate the reaction. The quantity of $\mathrm{H}_{2} \mathrm{O}_{2}$ was in excess since only $1.75 \mathrm{mM}$ of $\mathrm{H}_{2} \mathrm{O}_{2}$ is needed for total degradation of $20 \mathrm{mg} \mathrm{L}^{-1}$ solution of pollutant according to eqn (1).

$$
\mathrm{C}_{6} \mathrm{H}_{5} \mathrm{NO}_{4}+13 \mathrm{H}_{2} \mathrm{O}_{2} \rightarrow 6 \mathrm{CO}_{2}+15 \mathrm{H}_{2} \mathrm{O}+\mathrm{HNO}_{3}
$$

The whole was kept under magnetic stirring at $150 \mathrm{rpm}$. A control experiment without $\mathrm{H}_{2} \mathrm{O}_{2}$ was also conducted under the same conditions. At specific time intervals, $2 \mathrm{~mL}$ aliquots of the solution were withdrawn from the reaction mixture, filtrated using a $0.45 \mu \mathrm{m}$ PTFE membrane and analysed using an Ultraviolet-Visible Shimadzu UV-1650PC spectrophotometer. The remaining concentration in solution evaluated by measuring absorbance at $323 \mathrm{~nm}$ was used to calculate the abatement efficiency according to eqn (2).

$$
\text { Abatement efficiency }(\%)=\left(1-C / C_{0}\right) \times 100
$$

\section{Results and discussion}

\subsection{Materials characterization}

Powder X-ray diffraction patterns of the prepared biochars and their corresponding composites are depicted on Fig. 1a. It can be seen that all the BCT samples show a broad band around $2 \theta$ $=25^{\circ}$ which is characteristic of amorphous carbon materials. ${ }^{15}$ Furthermore, the $\left(\begin{array}{lll}1 & 0 & 0\end{array}\right)$ plane of carbon expected at $2 \theta=43.5^{\circ}$ was absent for all samples, owing to their low graphitization degree. The patterns of Fe-BCT show the presence of poorly crystallized $\alpha$-FeOOH peaks (JCPDS 29-0713) without any detectable impurity, confirming that $\mathrm{Fe}^{2+}$ ions were effectively transformed into goethite. In addition, the broad band of amorphous carbon is absent, probably because of the (110) diffraction line of goethite that peaks at $2 \theta=22^{\circ}$.

The presence of goethite in the composites was further confirmed by Raman analyses. Indeed, it can be seen from Fig. 1b that the Raman spectra of BCT samples present two peaks located at 1340 and $1590 \mathrm{~cm}^{-1}$, corresponding respectively to the disordered structure in the graphene layers of carbon materials ( $\mathrm{D}$ band) and to the vibration of $\mathrm{sp}^{2}$ bonded carbon atoms in a $2 \mathrm{D}$-hexagonal lattice (G band). ${ }^{35}$ The integrated intensity ratio $I_{\mathrm{D}} / I_{\mathrm{G}}$ was higher for the $\mathrm{BC}-7$ than for $\mathrm{BC}-$ 5 and BC-3, thus providing evidence of the formation of disordered amorphous carbon with increasing carbonization temperature. In addition to the $\mathrm{D}$ and $\mathrm{G}$ bands, the spectra of Fe-BC5 and Fe-BC7 samples clearly show two other peaks at 299 and $393 \mathrm{~cm}^{-1}$ which correspond to the two more intense Raman shifts of $\alpha$-FeOOH. ${ }^{28}$ However, the existence of those shifts is not evident on the spectrum of Fe-BC3 probably because of the fluorescence observed while analysing such sample. Hence, the Fe-BC3 sample was further analysed by using a $10 \%$ laser power filter. As results, the Raman spectrum revealed three peaks at 226,296 and $412 \mathrm{~cm}^{-1}$, corresponding respectively to the $\mathrm{A}_{1 \mathrm{~g}}$ and the $\mathrm{E}_{\mathrm{g}}$ modes of hematite (Fig. S4a $\uparrow$ ). ${ }^{36}$ Furthermore, the obtained spectrum showed a more intense $\mathrm{G}$ band. This suggests that using higher laser power in our case induced further carbonization of biochar and structural transformation of goethite contained in the material owing to local heating. It is also interesting to notice that plasma treatment did not considerably influence the perfect or imperfect and the disordered arrangement of atoms in the carbon structure during the deposition process as evident from Fig. S4b. $\dagger$ Indeed, it can be seen from this figure that the $I_{\mathrm{D}} / I_{\mathrm{G}}$ ratio values did not tremendously change when biochars were treated by plasma in the absence of iron sulphate. However, a further surface hydroxylation of biochar by the plasma species can be suspected according to FTIR analyses (Fig. S5†). Indeed, in addition to absorption bands related to the presence of goethite (namely the bands at 3233, $1124,978,886,792,609$ and $\left.423 \mathrm{~cm}^{-1}\right),{ }^{37}$ the FTIR spectra of Fe-BCT (compared to those of the corresponding BCT samples) show a strong band at $1384 \mathrm{~cm}^{-1}$. Such band which was not expected is also present on the spectra of the P-BC samples (Fig. S5b†) and corresponds to the in plane bending vibration of $\mathrm{C}-\mathrm{OH}$ bonds in carbon materials as reported by Afreen et al. ${ }^{38}$ and by Wang et al. ${ }^{39}$ This confirm that further hydroxylation of biochar occurred during goethite deposition owing to the presence of $\mathrm{HO}^{\circ}$ radicals in the plasma plume.

The XPS survey scan spectra of BC-5, Fe-BC5 and P-BC5 are depicted in Fig. 2a. In addition to $\mathrm{C} 1 \mathrm{~s}$ and $\mathrm{O}$ 1s peaks respectively around 284 and $533 \mathrm{eV}$, the spectrum of Fe-BC5 clearly shows peaks of Fe 3p (58.1 eV) and Fe 2p (712.2 and 726.1 eV). 

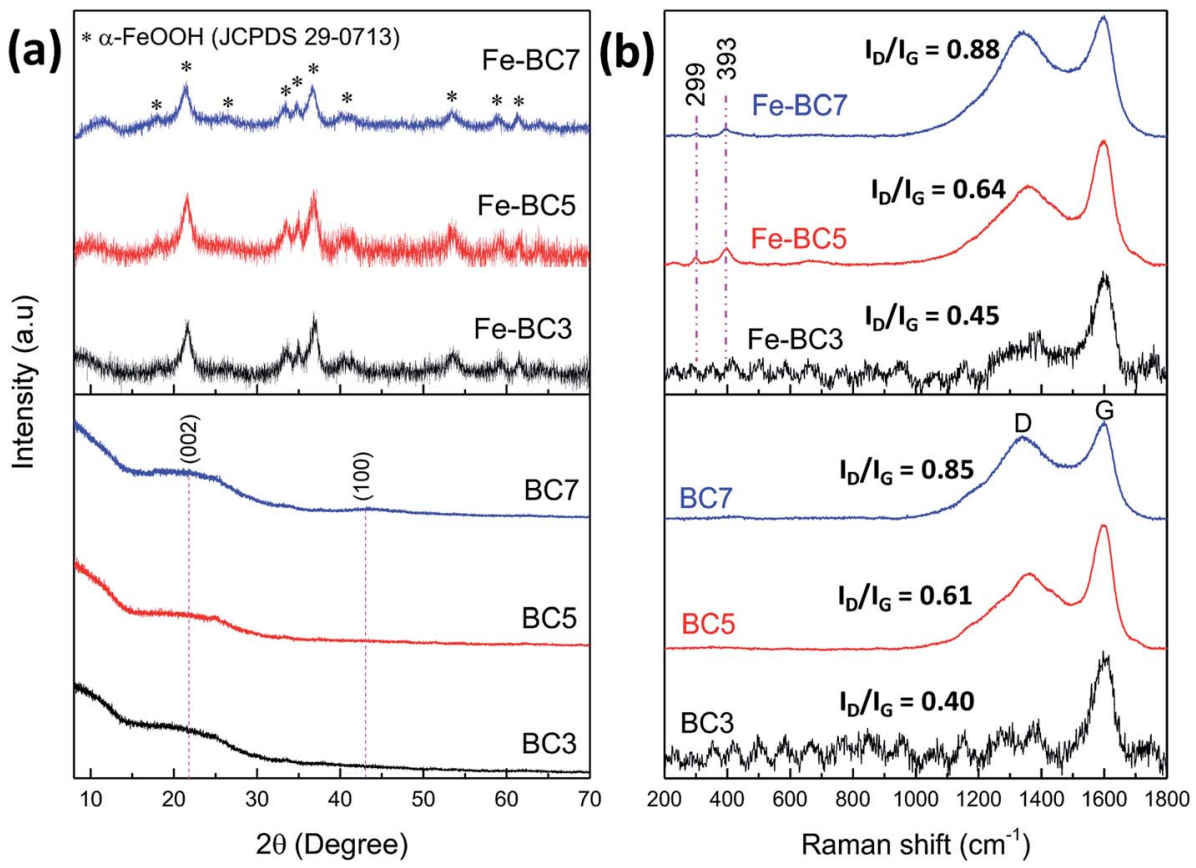

Fig. 1 (a) Powder XRD patterns and (b) Raman spectra (with 1\% laser power) of biochars obtained at different temperatures and the corresponding composites.

Moreover, the satellite peak around $720 \mathrm{eV}$ is clearly distinguishable on the high resolution spectrum of Fe 2p (Fig. 2b). Such peak has been ascribed to shake-up or charge transfer in $\mathrm{Fe}(\mathrm{III})$ oxides $^{40}$ and confirms the presence of $\alpha$-FeOOH in the composite.

All the XPS spectra show N 1s peak, suggesting that the raw biochar also contains traces of nitrogen. However, it can be seen from Table 1 that the surface nitrogen atomic percentage in PBC5 (entry 3) is higher than that in the non-treated BC5 (entry 1). This means that plasma treatment has undoubtedly induced a spontaneous $\mathrm{N}$-doping of materials. Obviously, the $\mathrm{NO}^{*}$ radicals that are among the main primary impinging species capable of reacting with solutes at the plasma-liquid interface could be accountable for such doping process. Similar results have been already obtained by Mbouopda et al. who found a spontaneous $\mathrm{N}$-doping of the target material during the synthesis of titanium oxide by humid air plasma ${ }^{41}$ High resolution $\mathrm{C}$ 1s spectra of $\mathrm{BC} 5$ and P-BC5 were deconvoluted into four main curves that peak at biding energies of approximately $284.3,285.2,286.4$ and $288.2 \mathrm{eV}$ corresponding respectively to aliphatic/aromatic carbon $(\mathrm{C}-\mathrm{C} / \mathrm{C}=\mathrm{C})$, adjacent to $\mathrm{C}-\mathrm{O}$ carbon ( $\underline{\mathrm{C}}-\mathrm{CO}$ ), $\mathrm{C}-\mathrm{O}$ and $\mathrm{C}=\mathrm{O}$ groups (Fig. $2 \mathrm{c}$ and $\mathrm{d}$ ). After plasma treatment of biochar, the peak intensity of $\mathrm{C}-\mathrm{C} / \mathrm{C}=\mathrm{C}$ group decreased while that of $\underline{\mathrm{C}}-\mathrm{O}$ and $\underline{\mathrm{C}}-\mathrm{CO}$ increased. As a consequence, the $\underline{\mathrm{C}}-\mathrm{O}$ and $\underline{\mathrm{C}}-\mathrm{CO}$ atomic percentage increased from $8.1 \%$ to $11.0 \%$ and $18.2 \%$ respectively. At the same time, the atomic percentage of O $1 \mathrm{~s}$ increased from $9.5 \%$ to $13.7 \%$. Such result further confirms the hydroxylation of biochar as stated before. It is worthy to note that $\underline{\mathrm{C}}-\mathrm{CO}$ atomic percentage which was equal to that of $\mathrm{C}-\mathrm{O}$ in $\mathrm{BC} 5$ became higher after plasma treatment, suggesting that the hydroxylation sites are those which tend to increase the number of carbon atoms adjacent to the $\mathrm{C}-\mathrm{OH}$ group. Otherwise, the $\underline{\mathrm{C}}-\mathrm{CO}$ atomic percentage would also be equal to that of $\mathrm{C}-\mathrm{O}$ in P-BC5. Mechanism described in Scheme 1 was thus proposed to explain the surface hydroxylation of biochar by $\mathrm{HO}^{*}$ radicals contained in plasma discharge. In such mechanism, we assume that the $\mathrm{HO}^{\circ}$ radicals (that act as reactive oxygen species) attack the carbon-carbon double bonds in the starting material, the consequence being the formation of polyhydroxylated carbon material. Silicon was also detected in all samples as natural impurity contained in raw biomass. ${ }^{23}$

The surface Fe atomic percentage in Fe-BC5 calculated from Fe 2 p XPS peak is $5.2 \%$ as presented in Table 1 . However, the mass content of $\alpha$-FeOOH in the prepared composites can be determined by thermogravimetry via oxidative decomposition of carbon contained in each composite. As it can be seen on Fig. S6, $\uparrow$ the TGA and DTA curves of each BCT sample shows two thermal phenomena between $30{ }^{\circ} \mathrm{C}$ and $500{ }^{\circ} \mathrm{C}$. The first phenomenon with an endothermal peak around $150{ }^{\circ} \mathrm{C}$ corresponds to the elimination of physisorbed water whereas the second one with exothermal peak around $300-500{ }^{\circ} \mathrm{C}$ corresponds to oxidative decomposition of biochar. Approximately $10 \%, 12 \%$ and $13 \%$ of the total mass was left after thermal decomposition of $\mathrm{BC} 3, \mathrm{BC} 5$ and $\mathrm{BC} 7$ respectively and was attributed to the residual $\mathrm{SiO}_{2}$ and other inorganic impurities present in the material. For the Fe-BCT samples an additional phenomenon with endothermal peak occurred around $250{ }^{\circ} \mathrm{C}$. Such phenomenon corresponds to goethite-to-hematite transformation as reported in our previous works. ${ }^{28}$ Accordingly, the goethite weight percentage in each composite was estimated by using eqn (3). 

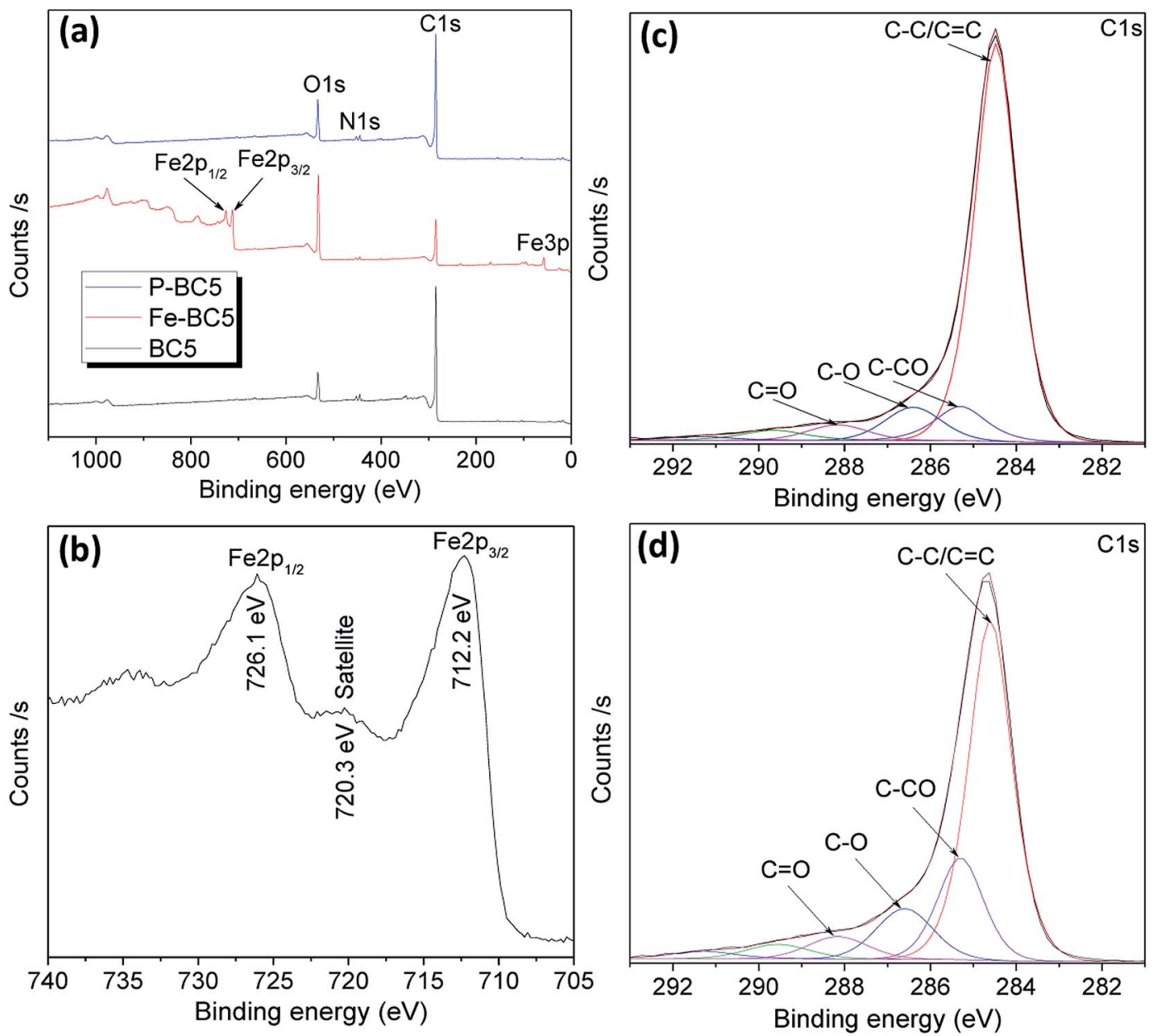

Fig. 2 (a) XPS survey of BC5, Fe-BC5 and P-BC5; (b) high resolution spectrum of Fe $2 p$ collected from Fe-BC5; (c) and (d) deconvoluted high resolution spectra of $C 1$ collected from $B C 5$ and $P-B C 5$ respectively.

$$
\% \alpha-\mathrm{FeOOH}=\left(\% m_{2}-\% m_{1}\right)+\% m_{3} .
$$

where: $\% m_{1}$ is the residual weight percentage after carbon oxidative decomposition in BCT, $\% m_{2}$ is the residual weight percentage after carbon oxidative decomposition in Fe-BCT, \% $m_{3}$ is the mass loss percentage corresponding to goethite-tohematite transformation.

Results presented in Table $\mathrm{S} 1 \uparrow$ show goethite weight contents of $48.5 \%, 55.5 \%$ and $55.7 \%$ for Fe-BC3, Fe-BC5 and FeBC7 respectively which are lower than the expected content of $58.3 \%$. Indeed, in a preliminary study, $0.7 \mathrm{~g}$ of goethite was obtained when a solution containing 0.0084 mole of iron sulfate was treated by plasma without biochar for the same time. This may be due to the fact that a part of hydroxyl radicals available to react with $\mathrm{Fe}^{2+}$ ions was consumed in the biochar hydroxylation process, thus limiting the goethite formation reaction. The lowest goethite content was obtained for Fe-BC3, probably because the BC3 sample still contained considerable amount of organic moieties that further reacted with hydroxyl radicals during the deposition process.

The SEM micrographs of BCT and Fe-BCT are depicted in Fig. 3. The images of BCT show microsize irregular plate-like structure with different thickness, the thinner being that of BC7 (Fig. 3a-c). The particles of the Fe-BCT samples are less

Table 1 Surface content of several elements contained in BC5, Fe-BC5 and P-BC5 as obtained from XPS analysis

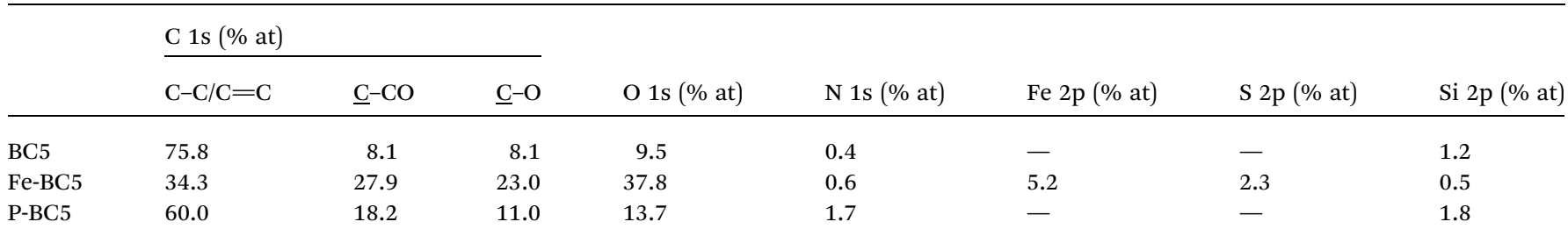




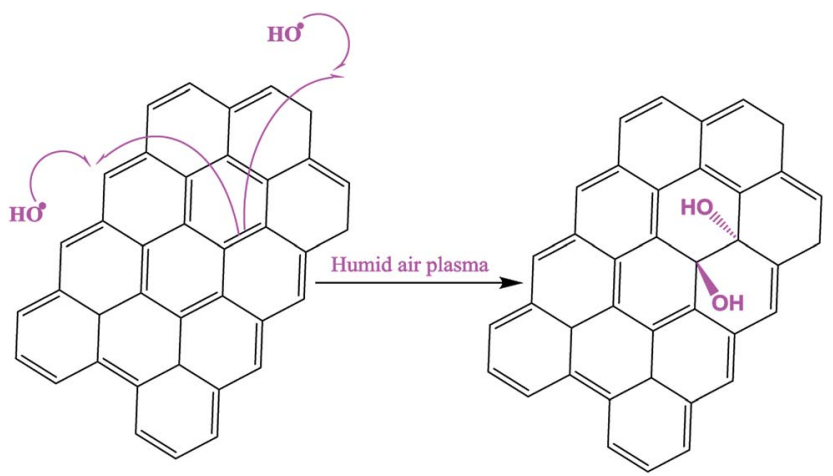

Scheme 1 Possible mechanism of biochar surface hydroxylation during $\alpha$-FeOOH deposition using humid air glidarc plasma.

smooth than those of the corresponding biochar (Fig. 3d-i) because of the presence of dispersed fibrous materials on their surface. The mapping images of Fe-BC5 (Fig. 3j) reveal a homogeneously distribution of iron on the BC5 surface suggesting that $\alpha$-FeOOH nanoparticles were densely grown on biochar.

The nitrogen adsorption-desorption isotherms of biochars and their corresponding goethite-coated composites are presented on Fig. 4. According to 2015-IUPAC technical report, ${ }^{42}$ the isotherm of BC3 depicts a type-II shape characteristic of non-porous or macroporous materials. Furthermore, no significant peak was observed on the Horvath-Kawazoe pores size distribution curve of $\mathrm{BC} 3$. This corroborate the low specific surface area $\left(4 \mathrm{~m}^{2} \mathrm{~g}^{-1}\right)$ and pore volume $\left(0.006 \mathrm{~cm}^{3} \mathrm{~g}^{-1}\right)$ values obtained for such material (Table 2, entry 1). The adsorption isotherms of BC5 and BC7 are of type I (with a slight occurrence of capillary condensation at high partial pressure), thus reflecting abundant microporous structure of such materials and the existence of few mesopores. Their Horvath-Kawazoe pores size distribution curves exhibit two maxima each (namely at 0.5 and $0.6 \mathrm{~nm}$ for $\mathrm{BC} 5$, and 0.5 and $0.8 \mathrm{~nm}$ for $\mathrm{BC} 7$ ) corresponding to slit-shaped pores usually developed by the intersheet space in carbon materials. ${ }^{43}$ The recorded isotherms of materials obtained after goethite deposition are a combination of type I and type IV with H3 hysteresis loop. Therefore, all the Fe-BCT materials displayed both micropores and mesopores, since type IV isotherm is usually obtained for mesoporous materials. However, a downward shift of the peak at $0.6 \mathrm{~nm}$ with respect to $x$ axis (for Fe-BC5) and that of the peaks at 0.5 and $0.8 \mathrm{~nm}$ with respect to $y$ axis (for $\mathrm{Fe}-\mathrm{BC} 7$ ) was observed after goethite deposition. Consequently, the microporous surface area decreased, excepted that of $\mathrm{BC} 3$ which increased from 4 to $26 \mathrm{~m}^{2} \mathrm{~g}^{-1}$. Meanwhile, the mesoporous surface area of all the materials increased. The final mesoporous surface area values of the prepared materials were almost the same (around $95 \mathrm{~m}^{2}$ $\mathrm{g}^{-1}$ ) suggesting that the observed difference in their specific surface area was due only to the difference in the initial surface area of the supports.

As a reminder, the FTIR and XPS results revealed that surface hydroxylation of biochar occurred during goethite deposition. In order to investigate to what extend such hydroxylation may
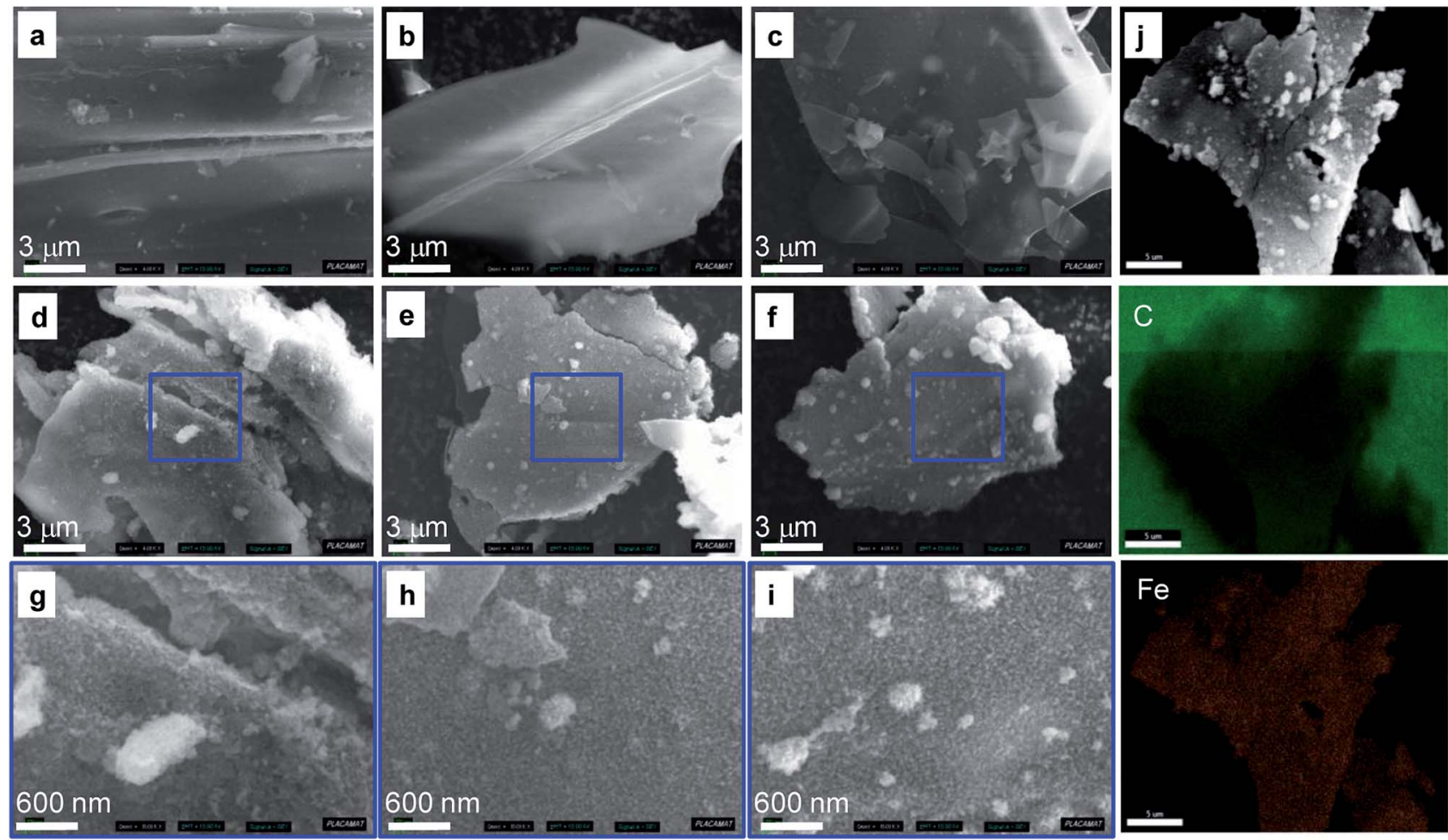

\section{h} $600 \mathrm{~nm}$
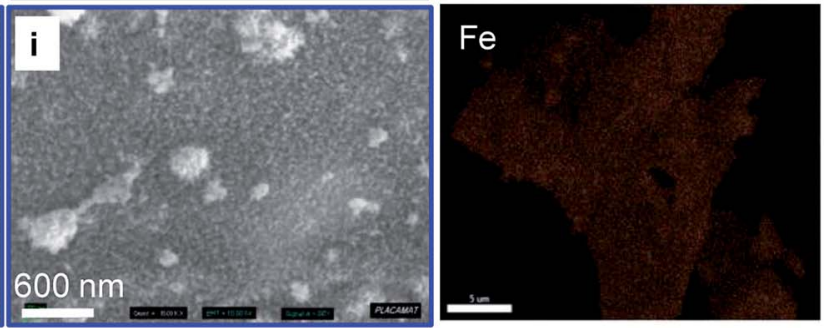

Fig. 3 SEM images of (a) BC3, (b) BC5, (c) BC7 and (d-i) SEM images of the corresponding Fe-BCT composites; (j) the carbon and iron EDS mapping images of Fe-BC5. 

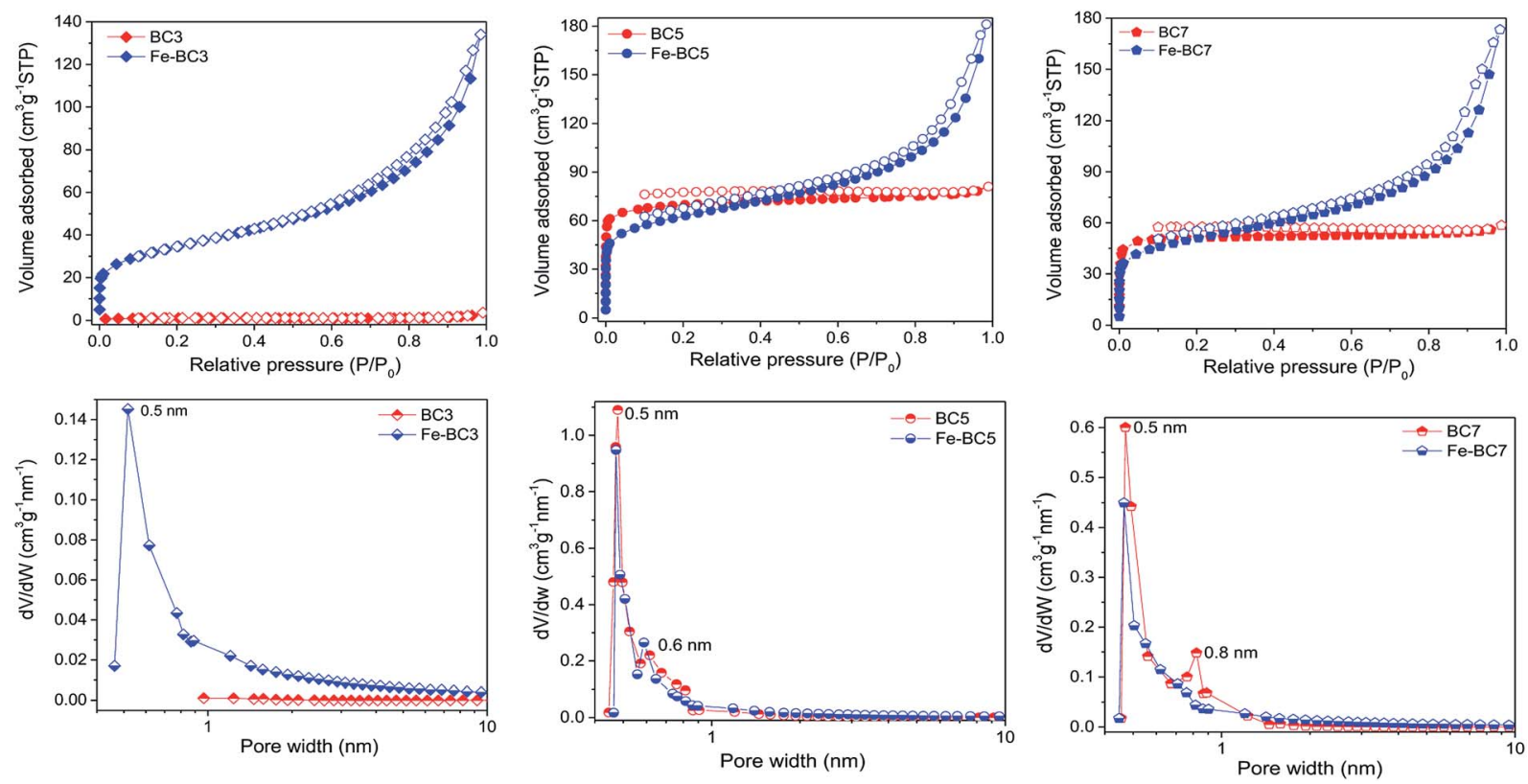

Fig. 4 Nitrogen adsorption-desorption isotherms (top) and the Horvath-Kawazoe pore size distribution curves (down) of BCT and Fe-BCT materials.

Table 2 Textural properties of BCT, Fe-BCT and P-BCT materials obtained from nitrogen physisorption at $-196^{\circ} \mathrm{C}$

\begin{tabular}{|c|c|c|c|c|c|c|}
\hline & $S_{\text {BET }}\left(\mathrm{m}^{2} \mathrm{~g}^{-1}\right)$ & $S_{\text {micro }}\left(\mathrm{m}^{2} \mathrm{~g}^{-1}\right)$ & $S_{\text {meso }}\left(\mathrm{m}^{2} \mathrm{~g}^{-1}\right)$ & $V_{\text {tot }}\left(\mathrm{cm}^{3} \mathrm{~g}^{-1}\right)$ & $V_{\text {micro }}\left(\mathrm{cm}^{3} \mathrm{~g}^{-1}\right)$ & $V_{\text {meso }}\left(\mathrm{cm}^{3} \mathrm{~g}^{-1}\right)$ \\
\hline BC3 & 4 & 4 & 0 & 0.006 & 0.002 & 0.002 \\
\hline BC5 & 266 & 252 & 14 & 0.125 & 0.103 & 0.015 \\
\hline Fe-BC3 & 119 & 26 & 94 & 0.207 & 0.013 & 0.143 \\
\hline Fe-BC5 & 221 & 125 & 96 & 0.280 & 0.057 & 0.172 \\
\hline Fe-BC7 & 179 & 85 & 94 & 0.268 & 0.039 & 0.169 \\
\hline P-BC7 & 179 & 171 & 8 & 0.084 & 0.068 & 0.010 \\
\hline$\alpha-\mathrm{FeOOH}$ & 121 & 23 & 98 & 0.205 & 0.011 & 0.148 \\
\hline
\end{tabular}

affect the textural properties of materials, BCT samples were also treated with plasma (in the absence of $\mathrm{Fe}^{2+}$ ions) and then analysed. As it can be seen on Fig. S7, $\uparrow$ BC3 became slightly mesoporous. However, no significant change in specific surface of BC3 was observed after plasma treatment. Oppositely, the nitrogen adsorption isotherms of BC5 and BC7 displayed a decrease in adsorbed volume at low partial pressure after plasma treatment while a drastic downward shift (with respect to $y$ axis) of the peak at $0.5 \mathrm{~nm}$ accompanied by the upward shift of that at 0.6 and $0.8 \mathrm{~nm}$ was respectively observed on their Horvath-Kawazoe pore sizes distribution curves. Accordingly, the microporous surface area (and thus the specific surface area) decreased as shown in Table 2. The microporous volume also decreased. However, the mesoporous volume remained quasi constant. This suggests that the decrease in microporous volume was not compensated by the formation of mesopores, but rather by the formation of bigger micropores. We thus suggested that the observed surface hydroxylation of biochar induced a partial deformation of carbon sheets as summarized by Scheme 2 .

\subsection{Catalytic activity tests}

The catalytic activities of the prepared materials are depicted on Fig. 5. The reaction was first catalysed by Fe-BC5 and the result was compared with that of the reaction catalysed by the bulk $\alpha$ FeOOH. It is noteworthy on Fig. 5a that nitroresorcinol was totally degrade within 40 min when Fe-BC5 $\left(1 \mathrm{~g} \mathrm{~L}^{-1}\right)$ was used as catalyst in the presence of $5 \mathrm{mM} \mathrm{H}_{2} \mathrm{O}_{2}$, while less than $20 \%$ of removal was found in control experiment without $\mathrm{H}_{2} \mathrm{O}_{2}$ and was attributed to pollutant adsorption on the material. However, only $86 \%$ of nitroresorcinol were degraded after 100 min when the same weight of bulk $\alpha$-FeOOH was used as catalyst. This suggests that biochar might contribute to the catalytic activity of Fe-BC5 since this composite contains only $55 \%$ of goethite, the active phase in Fenton catalysis. To ascertain such assumption, the BC5 sample was also tested and remarkable abatement efficiency was obtained ( $60 \%$ after $100 \mathrm{~min}$ of reaction). Obviously, reactive oxygen species (i.e. $\mathrm{HO}^{*}$ radicals) have been successfully produced by $\mathrm{H}_{2} \mathrm{O}_{2}$ activation with biochars and quantified by electron paramagnetic resonance spectroscopy in 


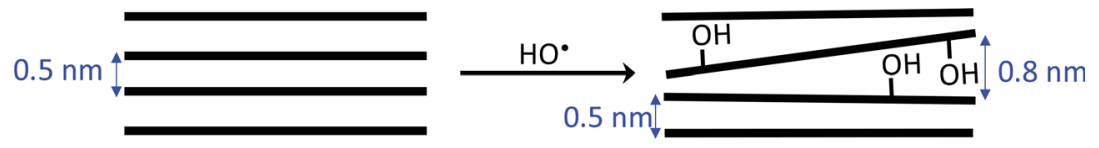

Scheme 2 Increased in slit pores size due to deformation of carbon sheets induced by surface hydroxylation of biochar.
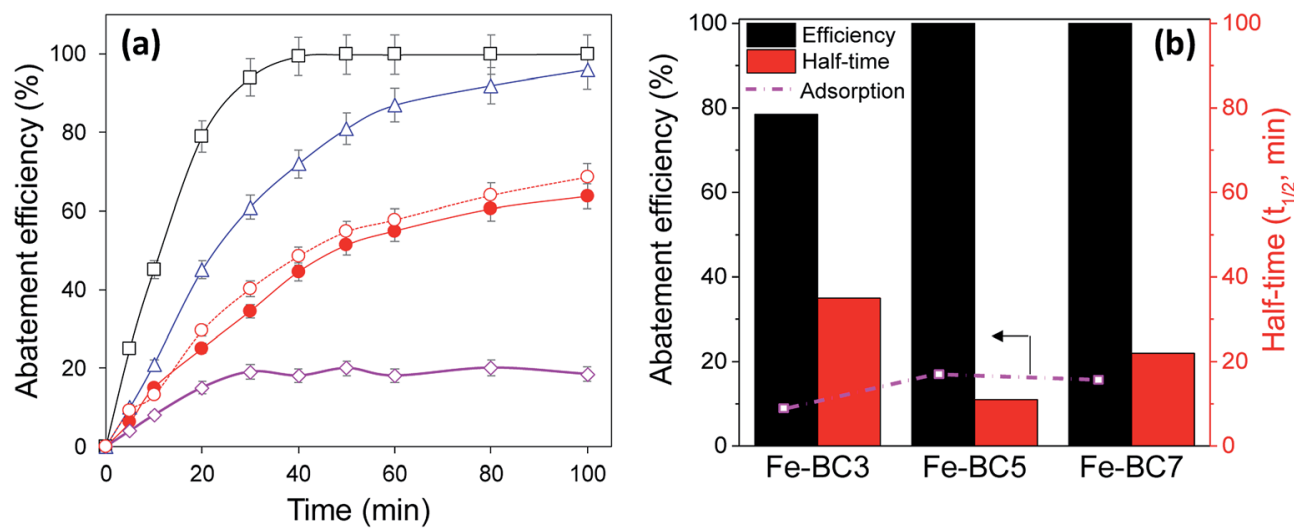

Fig. 5 (a) Evolution of nitroresorcinol abatement efficiency as a function of reaction time in the presence of prepared materials: ( $\square)$ Fe-BC5 + $\mathrm{H}_{2} \mathrm{O}_{2} ;(\Delta) \alpha-\mathrm{FeOOH}+\mathrm{H}_{2} \mathrm{O}_{2} ;(0) \mathrm{P}-\mathrm{BC} 5+\mathrm{H}_{2} \mathrm{O}_{2} ;(\bullet) \mathrm{BC} 5+\mathrm{H}_{2} \mathrm{O}_{2}$ and $(\bigotimes)$ Fe-BC5 only. (b) Nitroresorcinol abatement efficiency after 100 min and half-time of reactions catalysed by Fe-BCT materials $\left(C_{0}=20 \mathrm{mg} \mathrm{L}^{-1},\left[\mathrm{H}_{2} \mathrm{O}_{2}\right]=5 \mathrm{mM}\right.$; [catalyst $\left.]=1 \mathrm{~g} \mathrm{~L}^{-1} ; \mathrm{pH}^{2}=4\right)$.

recent studies. ${ }^{17}$ Thus, results herein obtained indicate that combining both processes by using iron coated biochar can lead to improve the catalytic performances in $\mathrm{H}_{2} \mathrm{O}_{2}$ activation.

Several papers have reported that carbon materials with great surface $\mathrm{C}-\mathrm{OH}$ groups have more activity for $\mathrm{H}_{2} \mathrm{O}_{2}$ decomposition. ${ }^{18,44}$ Therefore, the catalytic activity of P-BC5 was also tested, aiming at evaluating to what extend the observed plasma hydroxylation of biochar might improve its catalytic performances. As presented in Fig. 5a, the catalytic activity of PBC5 appears quite similar to that of BC5 probably because the biochar hydroxylation was not extended enough to induce a significant enhancement in catalytic activity. The Fe-BC5 catalyst exhibited greater nitroresorcinol abatement efficiency compared to Fe-BC7 and Fe-BC3 (Fig. 5b). Indeed $100 \%$ of nitroresorcinol abatement with a half-time of $11 \mathrm{~min}$ were obtained when Fe-BC5 was used as catalyst. When such catalyst was replaced by $\mathrm{Fe}-\mathrm{BC} 7$ and $\mathrm{Fe}-\mathrm{BC} 3$, respectively $100 \%$ and $78 \%$ of abatement efficiency with respective half-time of $22 \mathrm{~min}$ and 35 min were obtained. Control tests showed that less than $20 \%$ of pollutant were removed in the absence of $\mathrm{H}_{2} \mathrm{O}_{2}$ for all the materials. Higher adsorptive removal was observed for Fe-BC5. Since Fe-BC5 has the higher surface area, we suggested that the catalytic activity of the composites was linked with their specific surface area.

\section{Conclusion}

A gliding arc plasma was evaluated as a tool for goethite particles deposition on biochar. $\alpha$-FeOOH particles were homogeneously deposited on biochar sheets obtained from slow pyrolysis of raffia bamboo pith. In such process, the plasma species (mostly $\mathrm{HO}^{\circ}$ and $\mathrm{NO}^{\circ}$ radicals) produced from humid air reacted with $\mathrm{Fe}^{2+}$ ions, thus inducing their oxidative precipitation. A part of those species also reacted with biochar. As a consequence, further hydroxylation and N-doping of biochar occurred. The prepared materials were successfully used as catalyst for oxidative degradation of nitroresorcinol, a model water pollutant. Such process provides an environmentally sound since the only chemical used for goethite deposition is water saturated air which is a green, available and renewable reagent.

\section{Conflicts of interest}

There are no conflicts of interest to declare.

\section{Acknowledgements}

This work was financed by the Excellence Initiative of the "Université de Bordeaux" (IdEx-Bordeaux) program via the postdoctoral grant awarded to ATD. The authors also thank P. Legros and C. Labrugère Sarroste from the "PLAteforme de CAractérisation des MATériaux (PLACAMAT) for their respective help in SEM-EDS and XPS analyses.

\section{References}

1 M. V. Galkin, A. T. Smit, E. Subbotina, K. A. Artemenko, J. Bergquist, W. J. J. Huijgen and J. S. M. Samec, ChemSusChem, 2016, 9(23), 3280-3287.

2 X. Huang, O. M. Morales Gonzalez, J. Zhu, T. I. Korányi, M. D. Boot and E. J. M. Hensen, Green Chem., 2017, 19(1), 175-187.

3 X. Huang, C. Atay, J. Zhu, S. W. L. Palstra, T. I. Korányi, M. D. Boot and E. J. M. Hensen, ACS Sustainable Chem. Eng., 2017, 5(11), 10864-10874. 
4 E. M. Anderson, R. Katahira, M. Reed, M. G. Resch, E. M. Karp, G. T. Beckham and Y. Román-Leshkov, ACS Sustainable Chem. Eng., 2016, 4(12), 6940-6950.

5 C. Li, X. Zhao, A. Wang, G. W. Huber and T. Zhang, Chem. Rev., 2015, 115(21), 11559-11624.

6 A. Rodriguez, D. Salvachúa, R. Katahira, B. A. Black, N. S. Cleveland, M. Reed, H. Smith, E. E. K. Baidoo, J. D. Keasling, B. A. Simmons, et al., Base-Catalyzed, ACS Sustainable Chem. Eng., 2017, 5(9), 8171-8180.

7 T. Parsell, S. Yohe, J. Degenstein, T. Jarrell, I. Klein, E. Gencer, B. Hewetson, M. Hurt, J. I. Kim, H. Choudhari, et al., Green Chem., 2015, 17(3), 1492-1499.

8 Y. Yao, B. Gao, F. Wu, C. Zhang and L. Yang, ACS Appl. Mater. Interfaces, 2015, 7(19), 10634-10640.

9 Y. Zhao, L. Huang and Y. Chen, Environ. Sci. Pollut. Res., 2017, 24(33), 25889-25898.

10 S. Liu, X. Tan, Y. Liu, Y. Gu, G. Zeng, X. Hu, H. Wang, L. Zhou, L. Jiang and B. Zhao, RSC Adv., 2016, 6(7), 58715880.

11 X. Xiao, B. Chen, Z. Chen, L. Zhu and J. L. Schnoor, Insight into Multiple and Multilevel, Environ. Sci. Technol., 2018, 52(9), 5027-5047.

12 Y. Tong, B. K. Mayer and P. J. McNamara, Environ. Sci.: Water Res. Technol., 2016, 2(4), 761-768.

13 D. Mohan, A. Sarswat, Y. S. Ok and C. U. Pittman, Bioresour. Technol., 2014, 160, 191-202.

14 D. D. Sewu, P. Boakye and S. H. Woo, Bioresour. Technol., 2017, 224, 206-213.

15 P. Hu, H. Su, Z. Chen, C. Yu, Q. Li, B. Zhou, P. J. J. Alvarez and M. Long, Environ. Sci. Technol., 2017, 51(19), 1128811296.

16 S. Zhu, X. Huang, F. Ma, L. Wang, X. Duan and S. Wang, Environ. Sci. Technol., 2018, 52, 8649-8658.

17 G. Fang, J. Gao, C. Liu, D. D. Dionysiou, Y. Wang and D. Zhou, Environ. Sci. Technol., 2014, 48(3), 1902-1910.

18 D. Huang, Y. Wang, C. Zhang, G. Zeng, C. Lai, J. Wan, L. Qin and Y. Zeng, RSC Adv., 2016, 6(77), 73186-73196.

19 Q. Yan, Y. Lu, F. To, Y. Li and F. Yu, Catal. Sci. Technol., 2015, 5(6), 3270-3280.

20 S. Y. Oh, Y. D. Seo, K. S. Ryu, D. J. Park and S. H. Lee, Environ. Sci.: Processes Impacts, 2017, 19(5), 711-719.

21 D. W. Cho, G. Kwon, Y. S. Ok, E. E. Kwon and H. Song, ACS Appl. Mater. Interfaces, 2017, 9(15), 13142-13150.

22 P. Lisowski, J. C. Colmenares, O. Mašek, W. Lisowski, D. Lisovytskiy, A. Kamińska and D. Łomot, ACS Sustainable Chem. Eng., 2017, 5(7), 6274-6287.

23 L. Chen, S. Yang, X. Zuo, Y. Huang, T. Cai and D. Ding, Chem. Eng. J., 2018, 354, 856-865.

24 H. Lesueur, A. Czernichowski and J. Chapelle, Dispositif de Génération de Plasmas Basse Température par Formation de Décharges Electriques Glissantes, French Patent, No. 2,639,172, 1988.
25 A. Czernichowski, H. Lesueur, I. Czernichowski-Lauriol, C. Fouillac and J. P. Chapelle, Rocédé de Traitement Electro-chimique d'un Gaz Contenant de l'Hydrogène Sulfuré, French Patent, No. 2,646,099, 1989.

26 B. Benstaali, P. Boubert, B. G. Cheron, A. Addou and J. Brisset, Plasma Chem. Plasma Process., 2002, 22(4), 553571.

27 E. Acayanka, A. Tiya Djowe, S. Laminsi, C. C. Tchoumkwé, S. Nzali, A. Poupi Mbouopda, P. T. Ndifon and E. M. Gaigneaux, Plasma Chem. Plasma Process., 2013, 33(4), 725-735.

28 A. Tiya-Djowe, S. Laminsi, G. L. Noupeyi and E. M. Gaigneaux, Appl. Catal., B, 2015, 176-177.

29 F. W. B. Tatchemo, S. Nzali, G. Kamgang Youbi, A. Tiya Djowe, D. K. Saa, E. Acayanka, S. Laminsi and E. M. Gaigneaux, Top. Catal., 2017, 60(12-14), 962-972.

30 D. R. Merouani, F. Abdelmalek, M. R. Ghezzar, A. Semmoud, A. Addou and J. L. Brisset, Ind. Eng. Chem. Res., 2013, 52(4), 1471-1480.

31 N. R. S. Tagne, N. Ebénézer, N. Dieunedort, F. Didier, M. Fogue, J. Y. Drean and O. Harzallah, J. Nat. Fibers, 2017, 14(5), 621-633.

32 R. Jusoh, A. A. Jalil, S. Triwahyono and N. H. N. Kamarudin, RSC Adv., 2015, 5, 9727-9736.

33 C. Descorme, Catal. Today, 2017, 297, 324-334.

34 F. Audouin, M. Birot, É. Pasquinet, H. Deleuze, O. Besnard and D. Poullain, J. Appl. Polym. Sci., 2008, 108(5), 2808-2813.

35 M. Vadivazhagan, P. Parameswaran, U. Mani and K. Nallathamby, ACS Sustainable Chem. Eng., 2018, 6(11), 13915-13923.

36 J. Ma, Z. Zhu, B. Chen, M. Yang, H. Zhou, C. Li, F. Yu and J. Chen, J. Mater. Chem. A, 2013, 1(15), 4662-4666.

37 P. Cambier, Clay Miner., 1986, 191-200.

38 S. Afreen, K. Kokubo, K. Muthoosamy and S. Manickam, RSC Adv., 2017, 7(51), 31930-31939.

39 J. Wang, Z. Li, S. Li, W. Qi, P. Liu, F. Liu, Y. Ye, L. Wu, L. Wang and W. Wu, PLoS One, 2013, 8(8), e72475.

40 W. Yan, H. Liu, R. Chen, J. Xie and Y. Wei, RSC Adv., 2015, 5(129), 106396-106399.

41 A. P. Mbouopda, E. Acayanka, F. W. Boyom-Tatchemo, G. Y. Kamgang, A. M. Nzeufa, S. Laminsi and D. N. Richard, Mater. Chem. Phys., 2018, 206, 224-231.

42 M. Thommes, K. Kaneko, A. V. Neimark, J. P. Olivier, F. Rodriguez-Reinoso, J. Rouquerol and K. S. W. Sing, Pure Appl. Chem., 2015, 87(9-10), 1051-1069.

43 N. Brun, S. R. S. Prabaharan, M. Morcrette, C. Sanchez, G. Pécastaings, A. Derré, A. Soum, H. Deleuze, M. Birot and R. Backov, Adv. Funct. Mater., 2009, 19(19), 3136-3145.

44 G. D. Fang, C. Liu, J. Gao and D. M. Zhou, Ind. Eng. Chem. Res., 2014, 53(51), 19925-19933. 